\title{
Treatment of Chronic Traumatic Diaphragmatic Hernia Based on Laparoscopic Repair: Experiences From 23 Cases
}

\author{
Qiaonan Liu' ${ }^{1}$ Li Luan', Guangyong Zhang ${ }^{2}$ and Bo Li ${ }^{1 *}$ \\ ${ }^{1}$ Department of Hernia and Abdominal Wall Surgery, Shandong Provincial Qianfoshan Hospital, Shandong University, Jinan, \\ China, ${ }^{2}$ Department of Gastrointestinal Surgery, Shandong Provincial Qianfoshan Hospital, Shandong University, Jinan, China
}

\section{OPEN ACCESS}

Edited by:

Hubert Scheuerlein,

Klinik für Allgemein- und

Viszeralchirurgie, St.

Vincenz-Krankenhaus

$\mathrm{GmbH}$, Germany

Reviewed by:

Ulf Gunnarsson,

Umeå University, Sweden

Junsheng Li,

Southeast University, China

*Correspondence:

$\mathrm{BO} \mathrm{Li}$

libo197399@hotmail.com

Specialty section:

This article was submitted to Visceral Surgery,

a section of the journal

Frontiers in Surgery

Received: 08 May 2021 Accepted: 21 June 2021 Published: 15 July 2021

Citation:

Liu Q, Luan L, Zhang G and Li B (2021) Treatment of Chronic Traumatic

Diaphragmatic Hernia Based on Laparoscopic Repair: Experiences

From 23 Cases.

Front. Surg. 8:706824.

doi: 10.3389/fsurg.2021.706824
Background: We aimed to investigate the safety and effectiveness of laparoscopic repair for treating chronic traumatic diaphragmatic hernia $(\mathrm{CTDH})$.

Methods: In this retrospective analysis, we included 23 cases with CTDH underwent laparoscopy in our hospital between June 2015 and October 2019 was performed. The patient characteristics were recorded. We compared the diameter of hernia ring, surgery duration, intraoperative bleeding volume, means of repairing, as well as the follow-up data.

Results: All the patients underwent laparoscopic diaphragmatic hernia repair, without conversion to laparotomy or thoracotomy. The operation time ranged from $60 \mathrm{~min}$ to $200 \mathrm{~min}$ (mean, $108.04 \pm 42.93 \mathrm{~min}$ ). The blood loss volume ranged from 10 to $300 \mathrm{ml}$ (mean volume, $63.48 \pm 71.69 \mathrm{ml}$ ). The postoperative hospital stayed ranged from 5 to 15 days (mean, $6.22 \pm 2.11$ days). The patients were followed up for 1-50 months (mean, $17.5 \pm 10.90$ months). No recurrence of diaphragmatic hernia was found.

Conclusions: Laparoscopic repair of CTDH is featured by fast recovery, high security, and effectiveness. Reducing the hernia contents and close of the hernia ring are crucial for the surgery that is performed based on the size and location of the diaphragmatic hernia.

Keywords: laparoscopy, diaphragmatic hernia, laparotomy, thoracotomy, muscle flap

\section{INTRODUCTION}

Traumatic diaphragmatic hernia $(\mathrm{TDH})$, a spectrum of disease processes based on temporal patterns from acute to chronic (1), is a rare disease encountered in $0.8-6 \%$ of blunt trauma and more than $17 \%$ of thoraco-abdominal-penetrating trauma (2). Grimes divided TDH into 3 phases based on a similar schema designed by Carter and colleagues: 1 . Acute 2. Latent 3. Obstructive (3).

As the symptoms of TDH are usually insidious, over $30 \%$ of the patients with diaphragm injures would not present symptoms immediately after trauma. Abdominal organs herniated into the chest cavity would lead to clinical symptoms of different systems including chest symptoms (e.g., chest pain, tightness, shortness of breath, and dyspnea), abdominal symptoms (e.g., abdominal pain, nausea, vomiting, stop flatus and defecation, and other manifestations of intestinal obstruction, acid reflux, and belching), as well as the symptoms (e.g., chronic anemia). In cases 
of strangulation and necrosis in herniate organs, there might be signs of peritonitis, which is a great threat to the life of patients $(4,5)$.

Diaphragmatic hernia patients with no spontaneous remission are suggested to undergo surgery upon diagnosis $(4,6,7)$. To date, its treatment is highly relied on transthoracic, transabdominal and thoracoabdominal approaches $(4,5,8,9)$. However, there are disputes on the efficiency of these treatment options. For the cases with a large hernia ring, there might be challenges in the tissue repair even after the coverage using multiple meshes, leading to a high possibility of recurrence. To our best knowledge, rare studies focused on the feasibility of autologous muscle flaps for the closing of the hernia ring even of a large size forming bridge grafting. In this study, we retrospectively analyzed 23 cases of $\mathrm{CTDH}$ and summarized the surgical skills and experiences based on laparoscopic repair.

\section{MATERIALS AND METHODS}

\section{Patients}

Twenty-three patients with $\mathrm{CTDH}$ underwent laparoscopic herniorrhaphy in our department from June 2015 to October 2019 were included in this study. These confirmed with diaphragmatic hernia induced by trauma were eligible to this study upon confirmation using the $\mathrm{X}$ ray, CT scan, upper gastroenterography and MRI. The exclusion criteria were as follows: (a) those with severe immune and/or endocrine disorders, hepatic or renal insufficiency, with poor tolerance to surgery; (b) those with severe mental disorders, or those with severe cognitive dysfunction; (c) those with severe coagulation disorders. This was a retrospective analysis, and the informed consent was waived by the ethics committee of our hospital.

Most of the patients diagnosed with chronic TDH had been admitted to the hospital at the time of the trauma and had been discharged without a diagnosis of TDH after examination. A small part of cases presented mild diaphragmatic injuries, and they decided to choose conservative therapy.

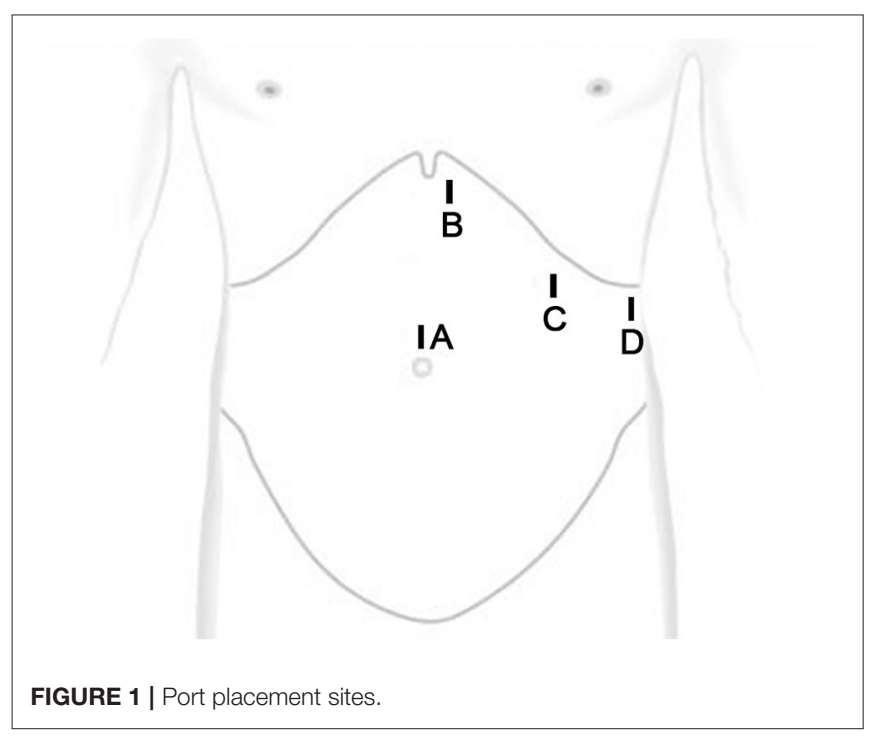

\section{Pre-surgical Protocol}

Before surgery, each patient underwent determination of cardiopulmonary function and coagulation test to exclude the contraindications for surgery and anesthesia. Gastrointestinal decompression was performed to the cases with intestinal obstruction. In addition, fasting fluid infusion and other symptomatic treatment were given before surgery. To improve the cardiopulmonary function, antibiotic was administrated to the patients with pulmonary infection.

\section{Surgical Procedures}

Each patient was in a fasting state before surgery, followed by insertion of gastric tube. General anesthesia was conducted using the double-lumen endotracheal intubation with a reverse Trendelenburg modified lithotomy position.

A longitudinal incision $(10 \mathrm{~mm})$ was made above the umbilicus, followed by insertion of laparoscope. Afterwards, trocars with a dimension of $5 \mathrm{~mm}, 12 \mathrm{~mm}$ and $5 \mathrm{~mm}$ were placed at the position that was about $3 \mathrm{~cm}$ to the left side beneath xiphoid process, $3 \mathrm{~cm}$ beneath costal margin of left midclavicular line, and $3 \mathrm{~cm}$ beneath the costal margin of left anterior axillary line, respectively (Figure 1). The size and location of the diaphragmatic hernia were confirmed, together with organ herniation into the thoracic cavity and adhesion to the surrounding tissues. The adhesion was carefully isolated along the hernia ring, and the omental tissues herniated into the thoracic cavity were dissected. Afterwards, the exudate in the hernia sac was aspirated. If necessary, 1-2 short gastric vessels can be cut. The organ herniated into the thoracic cavity was returned to the abdominal cavity with an atraumatic grasping forceps (Figure 2). In addition, attention should be paid to avoid grasping the organ during reduction. In cases of any difficulties, the hernia ring can be incised in a radiated pattern $(1-2 \mathrm{~cm})$ away from the pericardium with an electric coagulation hook to achieve release. The hernia ring was repaired by continuous suturing with non-absorbable sutures. For the lesions with a diameter of larger than $5 \mathrm{~cm}$, a suitable anti-adhesion mesh was utilized to reinforce the defect area. Fixation of the mesh was performed using surgical tacks, tissue glue and suture. For the treatment of 3 cases with a hernia ring of $>10 \mathrm{~cm}$, there was obvious fibrosis, it is still difficult to conduct direct suturing.

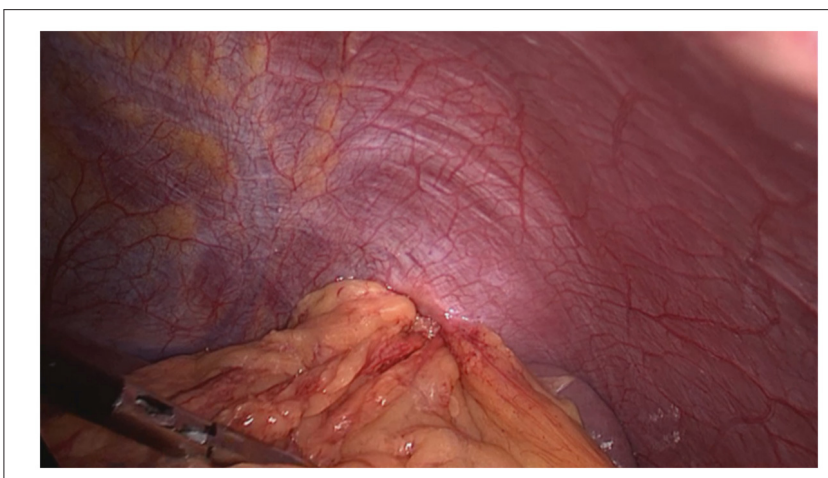

FIGURE 2 | Reducing hernia contents. 
TABLE 1 | Patient characteristics.

\begin{tabular}{|c|c|c|c|c|c|c|c|c|c|c|c|}
\hline Patient No. & Age, $y$ & Gender & Causes & $\begin{array}{l}\text { Preoperative } \\
\text { complication }\end{array}$ & Size, $\mathrm{cm}$ & Type of repair & $\begin{array}{l}\text { Secondary } \\
\text { injury }\end{array}$ & Blood loss, ml & $\begin{array}{l}\text { Operating } \\
\text { time, min }\end{array}$ & $\begin{array}{l}\text { Post-operative } \\
\text { complications }\end{array}$ & $\begin{array}{l}\text { Follow-up } \\
\text { time, month }\end{array}$ \\
\hline 1 & 51 & Male & Vehicle collision & Chest pain & 7 & Suture + Mesh & Small intestine & 80 & 170 & None & 50 \\
\hline 2 & 46 & Male & Vehicle collision & $\begin{array}{l}\text { Dyspnea, chest } \\
\text { pain }\end{array}$ & 6.5 & Suture + Mesh & None & 30 & 120 & None & 12 \\
\hline 3 & 37 & Male & Vehicle collision & $\begin{array}{l}\text { Dyspnea, } \\
\text { anemia }\end{array}$ & 8 & Suture + Mesh & None & 35 & 110 & None & 24 \\
\hline 4 & 60 & Female & Fall & $\begin{array}{l}\text { Anemia, lung } \\
\text { infection }\end{array}$ & 13 & Autologous tissue + mesh & $\begin{array}{l}\text { Splenic } \\
\text { hemorrhage, } \\
\text { colon injury }\end{array}$ & 100 & 200 & Pleural effusion & 36 \\
\hline 5 & 27 & Male & Vehicle collision & $\begin{array}{l}\text { Chest pain, low } \\
\text { fever }\end{array}$ & 4 & Suture & None & 10 & 80 & None & 24 \\
\hline 6 & 31 & female & Vehicle collision & Dyspnea & 5 & Suture + Mesh & None & 20 & 70 & None & 18 \\
\hline 7 & 41 & Male & Vehicle collision & $\begin{array}{l}\text { Low fever, } \\
\text { anemia }\end{array}$ & 7 & Suture + Mesh & Small intestine & 45 & 90 & Chest pain & 5 \\
\hline 8 & 63 & Male & Vehicle collision & $\begin{array}{l}\text { Gastrointestinal } \\
\text { obstruction }\end{array}$ & 7.5 & Suture + Mesh & Small intestine & 90 & 130 & Pleural effusion & 24.5 \\
\hline 9 & 50 & Female & Vehicle collision & $\begin{array}{l}\text { Lung infection, } \\
\text { anemia }\end{array}$ & 8 & Suture + Mesh & None & 65 & 100 & Low fever & 12 \\
\hline 10 & 70 & Female & Fall & $\begin{array}{l}\text { Gastrointestinal } \\
\text { obstruction, low } \\
\text { fever }\end{array}$ & 7.5 & Suture + Mesh & $\begin{array}{l}\text { Hemorrhage of } \\
\text { greater } \\
\text { omentum }\end{array}$ & 75 & 130 & None & 24 \\
\hline 11 & 72 & Male & Vehicle collision & $\begin{array}{l}\text { Dyspnea, } \\
\text { gastrointestinal } \\
\text { obstruction }\end{array}$ & 14 & Autologous tissue + mesh & $\begin{array}{l}\text { Small intestine } \\
\text { rupture, splenic } \\
\text { hemorrhage }\end{array}$ & 240 & 200 & $\begin{array}{l}\text { Chest pain, } \\
\text { pleural effusion }\end{array}$ & 24 \\
\hline 12 & 21 & Male & Fall & None & 3 & Suture & None & 15 & 70 & None & 12 \\
\hline 13 & 39 & Male & Vehicle collision & None & 5 & Suture + Mesh & None & 20 & 80 & None & 18 \\
\hline 14 & 38 & Female & Fall & $\begin{array}{l}\text { Low fever, } \\
\text { anemia }\end{array}$ & 6 & Suture + Mesh & Stomach & 30 & 100 & None & 24 \\
\hline 15 & 68 & Male & Vehicle collision & Lung infection & 6 & Suture + Mesh & None & 10 & 60 & Chest pain & 18 \\
\hline 16 & 51 & Male & Others & Stomach upset & 4 & Suture & None & 20 & 80 & None & 12 \\
\hline 17 & 36 & Female & Fall & None & 3 & Suture & Stomach & 60 & 90 & None & 12 \\
\hline 18 & 63 & Female & Vehicle collision & $\begin{array}{l}\text { Anemia, lung } \\
\text { infection }\end{array}$ & 6 & Suture + Mesh & $\begin{array}{l}\text { Small intestine } \\
\text { rupture }\end{array}$ & 100 & 140 & Pleural effusion & 12 \\
\hline 19 & 19 & Male & Vehicle collision & None & 3 & Suture & None & 20 & 60 & None & 18 \\
\hline 20 & 45 & Male & Vehicle collision & $\begin{array}{l}\text { Anemia, lung } \\
\text { infection }\end{array}$ & 5 & Suture + Mesh & None & 40 & 65 & Lung infection & 5 \\
\hline 21 & 71 & & & $\begin{array}{l}\text { Gastrointestinal } \\
\text { obstruction }\end{array}$ & 8 & Suture + Mesh & $\begin{array}{l}\text { Obstructive } \\
\text { necrosis of } \\
\text { transverse colon }\end{array}$ & 300 & 160 & $\begin{array}{l}\text { Lung infection, } \\
\text { pleural effusion }\end{array}$ & 1 \\
\hline 22 & 67 & Male & Vehicle collision & $\begin{array}{l}\text { Stomach upset, } \\
\text { cough }\end{array}$ & 11 & Autologous tissue + mesh & None & 25 & 120 & None & 12 \\
\hline 23 & 31 & Male & Vehicle collision & $\begin{array}{l}\text { Lung infection, } \\
\text { anemia }\end{array}$ & 5 & Suture + Mesh & Stomach & 30 & 60 & None & 5 \\
\hline
\end{tabular}


Therefore, a pedicle muscle flap was obtained from the anterior abdominal wall near the hernia ring. Then the flap was turned around to cover the defect, and then $2-0$ prolene suture was used to fix the pedicle muscle flap and the contralateral hernia ring. Finally, mesh was utilized to repair diaphragmatic hernia and abdominal wall defect. A drainage tube was inserted into the residual lumen of the hernia sac.

The gastric tube was removed on postoperative day 2 . The abdominal drainage tube was removed when the drainage volume was $<30 \mathrm{ml}$.

\section{Follow-Up}

The patient was followed up for 1-50 months (mean, $17.5 \pm$ 10.90 months). Each patient was required to receive physical examination at month $1,3,6,12$, and 24 after surgery. During the follow-up, each patient received CT and upper gastrointestinal radiography to monitor the recurrence and complications.

\section{RESULT}

\section{Patient Characteristics}

In this study, 23 cases were finally included. The demographic data, operation time, mechanism of injury, preoperative complications, the size of defect, type of repair, and follow-up time were listed in Table 1. None of the cases showed necrosis of the hernia contents.

\section{Treatment Efficiency}

Twenty-three patients in this group underwent diaphragmatic hernia repair via laparoscopic technique, with no necessity to convert to laparotomy or thoracotomy. Table 1 showed the operation time, blood loss, follow-up time, and post-operative complications of the 23 cases. In this study, the herniated tissues were recovered successfully in 20 cases. Three cases showed severe adhesion to the hernia sac with the herniated stomach, colon and spleen tissues, which was returned after release of adhesions. Four cases showed seromuscular damages in the gastric wall. One case showed seromuscular rupture in small intestine and colon, which were sewed up under laparoscope. One case presented splenic capsule rupture and bleeding, and then hemostasis was given by electric coagulation hook after reduction. Upon reduction of the hernia contents, the hernia ring and peripheral area $(5 \mathrm{~cm})$ were completely exposed (Figure 3). Subsequently, the diaphragmatic defect was intermittently sutured with 2-0 non-absorbable sutures. No one showed recurrence of diaphragmatic hernia. Patients with postoperative complications showed attenuation after conservative treatment.

The hernia ring with a diameter of $<5 \mathrm{~cm}$ can be directly sutured and repaired (Figure 4A). In the presence of a hernia ring with a diameter of $\geq 5 \mathrm{~cm}$, anti-adhesion mesh with an appropriate size was used for fixation at a position that was about $3-5 \mathrm{~cm}$ beyond the edge of hernia ring. In this group, Sepramesh (Bard) was used for repair, and fixation was conducted using the Fixation Device Covidien [ProTack((SP))TM((/SP))] (Figures 4B,C). During the fixation, glue and continuous suturing were utilized in the position that was close to the heart,

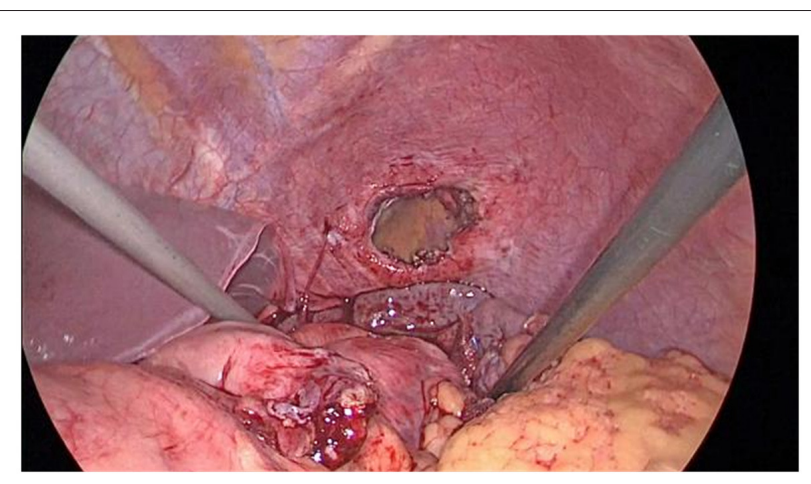

FIGURE 3 | The hernia ring and surrounding area should be exposed at least $5 \mathrm{~cm}$ after reducing the contents of the hernia.

pericardium, aorta and esophagus (10). Three cases showed huge hernia rings $(\geq 10 \mathrm{~cm}$ ) which could not be sutured. Pedicle muscle flaps with appropriate sizes were formed by separating the anterior abdominal wall tissues adjacent to the hernia rings, and then the flaps were inverted to close the contralateral hernia ring (Figures 4D-F). The diaphragmatic hernia and abdominal wall defect (i.e., the muscle flap free site) were repaired simultaneously using an anti-adhesive mesh, avoiding the "bridging repair" of the diaphragm. An abdominal drainage tube was placed in the residual cavity of the hernia sac, and no closed thoracic drainage tube was placed.

\section{Follow-Up}

For the follow-up, all the patients were followed up for $17.5 \pm 10.90$ months (1-50 months). For the disease recurrence and complications, CT and upper gastrointestinal radiography indicated that no one showed recurrence and severe complications.

\section{DISCUSSION}

About $90 \%$ diaphragmatic hernia occur on the left side, while the right diaphragm is usually protected by the liver with a small chance of TDH $(5,11-13)$. Our data were in line with these literatures. All the patients with $\mathrm{CTDH}$ may not present spontaneous remission (14). Besides, the area of diaphragmatic injury will be extended over time (15). On this basis, these patients are recommended to receive surgery as early as possible upon diagnosis.

Compared with congenital diaphragmatic hernia (e.g., hiatal hernia), severe adhesion of herniate organs was noticed in $\mathrm{CTDH}$, which resulted in vague landmark in the planes and normal anatomical structures. Therefore, it is essential to properly dissect the hernia sac to avoid injury to the surrounding viscera (16).

As diaphragmatic defect edges were weak, thin and fragile (17), there was usually a large tension when suturing the diaphragm, especially the part adjacent to the central of the hiatus. Thus, mesh repair was required for these cases (18). According to our experiences, for the hernia ring with a diameter 

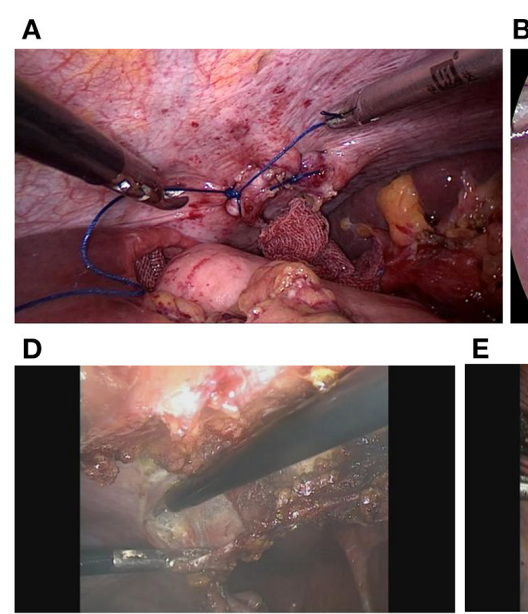

E
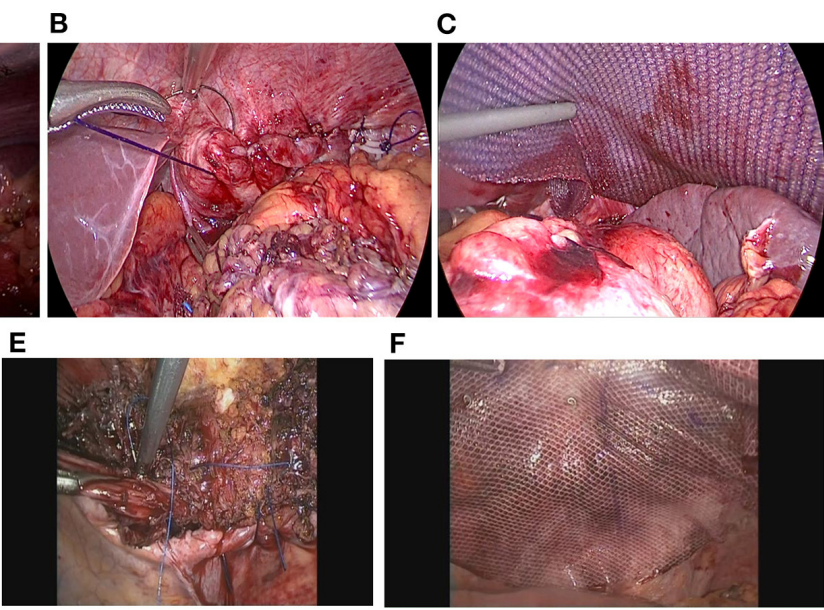

$\mathbf{F}$

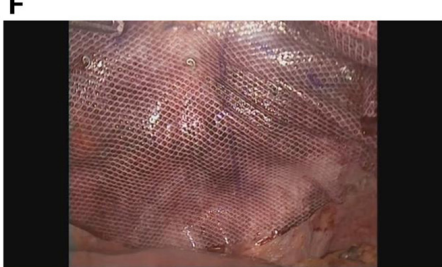

FIGURE 4 | Suture of the hernia ring with various sizes. (A) For the hernia ring with a diameter of $<5 \mathrm{~cm}$, single suture was given. (B,C) Suturing and mesh fixation were utilized for the treatment of hernia ring in a range of $5-10 \mathrm{~cm}$. (D-F) The muscle flap formed by the incision of anterior abdominal wall tissues, together with suture and mesh, were utilized to close the giant hernia ring with a diameter of $\geq 10 \mathrm{~cm}$.

of $<5 \mathrm{~cm}$, mesh may not be necessary if the diaphragmatic defect could be easily sutured. Nevertheless, mesh is recommended for the management of hernia ring with a diameter of $\geq 5 \mathrm{~cm}$. After taking the special anatomy of diaphragm into consideration, the diaphragmatic defect should be closed to avoid "bridging repair." In this study, we innovatively utilized the muscle flap formed by the incision of anterior abdominal wall tissues to close the giant hernia ring $(10 \mathrm{~cm})$. In addition, the diaphragmatic hernia and abdominal wall defect near the muscle flap free site were repaired with a big anti-adhesion mesh. These procedures were easy to perform and showed reliable efficiency for the repair.

Compared with laparotomy and thoracotomy, laparoscopic repair is superior in treating $\mathrm{CTDH}$ as it involves minimally invasive procedures, including less trauma, faster recovery, and shorter hospital stay (5). Compared with thoracoscopic surgery, laparoscopy contributed to the complete exploration of the entire abdominal cavity, which could illustrate the presence of adverse events such as hemorrhage and gastrointestinal rupture (19). For the cases with hemorrhage and gastrointestinal rupture, the lesions could be managed directly under the laparoscopic guidance, which was superior to the thoracoscopy. Simultaneously, it is much more difficult to fix the mesh to the thoracic surface of the diaphragm than to the abdominal surface of the diaphragm. The transabdominal approach is more exact for the repair effect. Indeed, the disease course of diaphragmatic hernia is comparatively longer, together with obvious adhesion, which triggered the difficulty in organ recovery into the abdominal cavity. Therefore, there is a harsh technical demanding for the treatment of CTDH under the guidance of laparoscopy. In cases of severe adhesion and difficulty in return of hernial content, gastrointestinal tract injury or bleeding during the surgery, the patients are recommended to undergo immediate laparotomy or thoracotomy.

Indeed, there are some limitations in our study. The sample size is not large, and the follow-up duration is not long. Besides, the interval between the initial injury and TDH symptoms is comparatively long, and then we could not obtain the clinical data for the first presentation. In future, more studies involving a large sample size and a long follow-up are required to further illustrate the efficiency of such regimen for the treatment of CTDH.

\section{CONCLUSION}

Laparoscopic technique is effective for treating $\mathrm{CTDH}$ as it triggers generation of clear surgical fields. Meanwhile, it is able to manage the adverse events simultaneously. The key point for the surgery is the reduction of hernia contents and the closure of hernia ring. In this study, the pedicle muscle flap we utilized was formed by freeing the anterior abdominal wall tissues close to the hernia ring and suturing the defect with the contralateral hernia ring tissue, which avoided the presence of "bridging repair" caused by incomplete hernia ring closure. Such technique is worthy of being widely popularized in the clinical application.

\section{DATA AVAILABILITY STATEMENT}

The original contributions presented in the study are included in the article/supplementary material, further inquiries can be directed to the corresponding author/s.

\section{ETHICS STATEMENT}

The studies involving human participants were reviewed and approved by the Ethics Committee of Qianfoshan Hospital of Shandong University. The patients/participants provided their written informed consent to participate in this study. 


\section{AUTHOR CONTRIBUTIONS}

QL wrote the manuscript. BL revised the manuscript. GZ did the data analysis. LL did the data collection. All authors read and approved the final manuscript.

\section{REFERENCES}

1. Gu $\mathrm{P}, \mathrm{Lu} \mathrm{Y}, \mathrm{Li} \mathrm{X}, \mathrm{Lin} \mathrm{X}$. Acute and chronic traumatic diaphragmatic hernia: 10 years' experience. PLoS ONE. (2019) 14:e0226364. doi: 10.1371/journal.pone.0226364

2. Blitz M, Louie BE. Chronic traumatic diaphragmatic hernia. Thorac Surg Clin. (2009) 19:491-500. doi: 10.1016/j.thorsurg.2009.08.001

3. Grimes OF. Traumatic injuries of the diaphragm: diaphragmatic hernia. Am J Surg. (1974) 128:175-81.

4. King BW, Skedros JG, Glasgow RE, Morrell DG. Resolution of chronic shoulder pain after repair of a posttraumatic diaphragmatic hernia: a 22-year delay in diagnosis and treatment. Case Rep Orthop. (2020) 2020:7984936. doi: 10.1155/2020/7984936

5. Tessely H, Journé S, Therasse A, Hossey D, and Lemaitre J. A case of colon necrosis resulting from a delayed traumatic diaphragmatic hernia. J Surg Case Rep. (2020) 2020:rjaa101. doi: 10.1093/jscr/rjaa101

6. Siow SL, Wong CM, Hardin M, Sohail M. Successful laparoscopic management of combined traumatic diaphragmatic rupture and abdominal wall hernia: a case report. J Med Case Rep. (2016) 10:11. doi: 10.1186/s13256-015-0780-8

7. Lesiå,Ski J, Zielonka TM, Kaszyå,Ska A, Wajtryt O, Pepliå,Ska K. $\AA ̊ y c i \AA ̊ n$,ska K, et al. Clinical manifestations of huge diaphragmatic hernias. Adv Exp Med Biol. (2018) 1039:55-65.

8. Furák J, Athanassiadi K. Diaphragm and transdiaphragmatic injuries. J Thorac Dis. (2019) 11 (Suppl. 2):S152-7. doi: 10.21037/jtd.2018.10.76

9. Porojan VA, David OI, Coman IS, Coman EV, Draghici DA, Popescu C, et al. Traumatic diaphragmatic lesions - considerations over a series of 15 consecutive cases. Chirurgia. (2019) 114:73-82. doi: 10.21614/chirurgia.114.1.73

10. Shao G, Wu L, Li J, Dai C. Laparoscopic diaphragmatic hernia repair with mesh reinforcement. Am Surg. (2020) 86:476-9. doi: $10.1177 / 0003134820919735$

11. Pulido J, Reitz S, Gozdanovic S, Price P. Laparoscopic repair of chronic traumatic diaphragmatic hernia using biologic mesh with cholecystectomy for intrathoracic gallbladder. Jsls. (2011) 15:546-9. doi: 10.4293/108680811X13176785204472

12. Iadicola D, Branca M, Lupo M, Grutta EM, Mandalà S, Cocorullo G, et al. Double traumatic diaphragmatic injury: a case report. Int J Surg Case Rep. (2019) 61:82-5. doi: 10.1016/j.ijscr.2019.07.030

\section{FUNDING}

This study was supported by the Project of science and technology of Shandong Provience (grant no. 2017GSF18151).

13. Xiao JC, Ma LY, Li BL. Late traumatic diaphragmatic rupture complicated by haemothorax and strangulation of the stomach: a case report. J Int Med Res. (2020) 48:300060520930864. doi: 10.1177/03000605209 30864

14. Petrone P, Asensio JA, Marini CP. Diaphragmatic injuries and post-traumatic diaphragmatic hernias. Curr Probl Surg. (2017) 54:11-32. doi: 10.1067/j.cpsurg.2016.11.001

15. Bhatti UH, Dawani S. Large bowel obstruction complicating a posttraumatic diaphragmatic hernia. Singapore Med J. (2015) 56:e56-8. doi: 10.11622/smedj.2015061

16. Liao $\mathrm{CH}$, Chu $\mathrm{CH}, \mathrm{Wu}$ YT, Fu CY, Hsieh FJ, Wang SY, et al. The feasibility and efficacy of laparoscopic repair for chronic traumatic diaphragmatic herniation: introduction of a novel technique with literature review. Hernia. (2016) 20:303-9. doi: 10.1007/s10029-015-1405-2

17. Aborajooh EA, Al-Hamid Z. Case report of traumatic intrapericardial diaphragmatic hernia: laparoscopic composite mesh repair and literature review. Int J Surg Case Rep. (2020) 70:159-63. doi: 10.1016/j.ijscr.2020. 04.077

18. Spiliotopoulos K, de la Cruz KI, Gkotsis G, Preventza O, Coselli JS. Repair of Intrapericardial diaphragmatic hernia during aortic surgery in a 78year-old woman. Tex Heart Inst J. (2017) 44:150-2. doi: 10.14503/THIJ-165985

19. Campos Costa F, Cardoso V, Monteiro AM, Guerreiro J. Laparoscopic repair of an acute traumatic diaphragmatic hernia: clinical case. Cureus. (2020) 12:e11082. doi: 10.7759/cureus.11082

Disclaimer: The authors alone are responsible for the content and writing of the article.

Conflict of Interest: The authors declare that the research was conducted in the absence of any commercial or financial relationships that could be construed as a potential conflict of interest.

Copyright (c) $2021 \mathrm{Liu}$, Luan, Zhang and Li. This is an open-access article distributed under the terms of the Creative Commons Attribution License (CC BY). The use, distribution or reproduction in other forums is permitted, provided the original author(s) and the copyright owner(s) are credited and that the original publication in this journal is cited, in accordance with accepted academic practice. No use, distribution or reproduction is permitted which does not comply with these terms. 